\title{
Surgical Endoscopy: An Update
}

\author{
Mark Talamini
}

Published online: 10 March 2010

(c) The Author(s) 2010. This article is published with open access at Springerlink.com

Having assumed the coeditorship of Surgical Endoscopy, I am humbled by the opportunity to serve Surgical Endoscopy, the Society of American Gastrointestinal and Endoscopic Surgeons (SAGES), and the surgical community in this position.

Surgical Endoscopy was born in 1987 by Springer, and shortly thereafter became the official publication first of the European Association of Endoscopic Surgeons (EAES) and then SAGES. At that time, the societies' areas of interest could be described as applying to only a small segment of surgeons. Through the growth of both societies in significance and impact and with the excellent tenures of the previous editors, the impact of Surgical Endoscopy also has increased.

As founding editor, B. C. Manegold put Surgical Endoscopy on solid footing. Alfred Cuschieri, Ken Forde, and Bruce MacFadyen oversaw the journal through a time of expansive growth of both the societies and Surgical Endoscopy.

Surgical Endoscopy currently stands as an important surgical journal growing in influence. Over the past 3 years, the impact factor has grown from 1.969 to a most recently reported 3.231. It currently has the 18th highest impact factor among 147 surgery journals ranked by Journal Citation Reports (Thomson Reuters). At the same time, we are working to improve the overall flow of the journal, which has indeed been a challenge given its increasing popularity and thus the number of submitted manuscripts.

The medical publishing world also is changing dramatically. The societies that Surgical Endoscopy represents are committed to being on the cutting edge of surgery. In parallel, Surgical Endoscopy also aims to adapt to the rapidly changing world of publishing. Online First publication, initiated during the coeditorships of Bruce MacFadyen and Alfred Cuschieri, continues to shorten the time from manuscript submission to dissemination. Currently, the average time from final acceptance of a manuscript to its publication online is 33 days. Dynamic manuscripts, those in which the online manuscript has links to dynamic content, will continue to increase in number. And a number of other new developments are coming.

I am confident that these changes will continue to strengthen Surgical Endoscopy and that it will continue to progress in importance and impact. But no journal improves without the support of its society members and its readers. I hope you will continue to send your manuscripts, which document the ongoing advancement of surgery, to us.

Open Access This article is distributed under the terms of the Creative Commons Attribution Noncommercial License which permits any noncommercial use, distribution, and reproduction in any medium, provided the original author(s) and source are credited.

M. Talamini $(\bowtie)$

Department of Surgery, University of California,

San Diego, USA

e-mail:mtalamini@ucsd.edu; talamini@ucsd.edu 